$\left.\begin{array}{c}\text { INTERNATIONAL JOURNAL OF } \\ \text { ORGANIZATIONAL LEADERSHIP }\end{array}\right) \begin{gathered}\text { INDUSTRIAL } \\ \text { MANAGEMENT } \\ \text { INSTITUTE }\end{gathered}$

\title{
The interaction of the performance factors in ACHIEVE model: A study in Iran
}

\author{
Nasim Yousef Saber ${ }^{1}$, Seyyed Mohsen Tabatabaei ${ }^{2}$, Abbas Afrazeh ${ }^{3}$ \\ ${ }^{1}$ MS Student, Department of Industrial Engineering, Amirkabir University of Technology \\ ${ }^{2} \mathrm{PhD}$ Candidate of Industrial Engineering, Amirkabir University of Technology \\ ${ }^{3}$ Faculty Member of Industry Department, Amirkabir University of Technology
}

\begin{abstract}
Keywords:

Performance Factors, ACHIEVE Model, Multiplicative Interactions, Reducing Interaction, Improving the Performance

Correspondence: nasim_saber@aut.ac.ir

According to the ACHIEVE model, seven factors including ability, clarity of roles, organizational support and help, incentive or motivation, evaluation and feedback, validity, and environmental factors affect employee performance. The purpose of this study was to evaluate the interaction among these performance factors. The population for the study consisted of 44 employees in a Web-based software manufacturing company in Iran. Data was collected through a questionnaire relevant to the factors of ACHIEVE. Data analysis was performed using correlation analysis in SPSS. The results of correlation analysis showed that some of these factors had a multiplicative interaction and some others had no interaction. There was also no evidence of reducing interaction. For example, the ability was not associated with other factors. In contrast, incentive and organizational support had some interactions. The article offers management recommendations for decision-making to improve the performance factors. Following this, identifying the effects helps managers to improve their performances.
\end{abstract}

\section{Introduction}

Performance management is an important aspect of organizational effectiveness (Cardy, 2004) because it is a key procedure by which the work is best done and has a high priority for 
managers (Pulakos, 2009). Although the performance appraisal is at the central part of performance management (Cardy, 2004), the whole process expands to all organizational policies, activities, and design features which interact and aims to improve the employee's performance. This prospect offers a sequential approach to human resource management. The pattern specified for human resource activities like other business activities are necessary to achieve organizational objectives (Delery \& Doty, 1996). As Armstrong (2000) stated, performance management process provides an opportunity for all compositional strategies. Following this, the entire process is extended to organizational policies, practices, and design features.

Performance management is an ongoing process that always looks to improve employee's performance. To improve performance, we need to know what factors might affect the performance. Various models, including ACHIEVE model studied factors affecting performance. However, a few studies have been done to study the interactions between these factors. This article attempts to answer this research gap by examining the interrelationship of the seven factors of ACHIEVE model in an Iranian company and determine the presence or absence of these relationships in that company.

\section{The Literature Review}

How to improve the staff's performance and achieve better outcomes is a question that has received ever-increasing attention and considerable focus in public sector (Moynihan \& Pandey, 2005, 2010; Wholey, 2001). To date, this issue has been studied from different perspectives in various contexts. Sun and Van Ryzin (2014) investigated the relationship between performance management practices by school leaders and educational outcomes. The results indicated that schools that perform a satisfactory and effective job at performance management indeed have better outcomes, even when controlling for student, staff, and school characteristics. The findings showed that student academic outcomes may be influenced by performance management practices. Performance management is widely regarded to be an effective strategy for improving outcomes in the public sector. Public managers can create an environment supporting innovation and performance through the use of performance management means (Jacobsen \& Andersen, 2014).

Helden, Johnsen, and Vakkuri (2012) discussed how performance management systems may be conceptualized as means for life cycle consisting of several stages. The life cycle 
approach facilitates a pervasive mapping of the various performance management stages and their probabilities from invention to assessment and re-designs.

Cho and Lee (2012) examined the relationship between performance management and two outcomes including perceived work-unit performance and perceived agency performance. They also tested the role of trust as a developer of the strong implementation of performance management. The results approved that performance management increased perceived performance of both work-unit and agency.

Bititci, Coccab and Ates (2015) investigated how visual strategy and performance management techniques influence performance measurement and management practices of organizations. The implementation cases showed that visual management systems guide ongoing strategy development and implementation and simplify performance measurement. Haines III and St-Onge (2012) probed into the mutual influence of practices and context on performance management effectiveness and found positive relationship between practices and performance management effectiveness.

An important factor to increase the results of an organization is to develop the performance drive of the workforce. Recently a tool called the performance management analysis (PMA) was created that helps an organization assess its degree of performance drive. De Waal, Hafizi, Rahbar, and Rowshan (2010) demonstrated that PMA is completely useful in Iran to come up with recommendations for further improvement. The purpose of the research done by O’Boyle and Hassan (2014) was to examine the current field of organizational performance management and measurement within non-profit sport organizations.

In a study examining the effect of a pair of organizational factors on the levels of performance management success, Ammons, Liston, and Jones (2013) found that local governments that regard performance management to be their management philosophy perceive greater benefits on particular aspects of performance than those regarding it to be a system of elevating performance measurement.

\section{The Study}

\section{Performance Factors of ACHIEVE Model}

In this study, seven-factor performance model which is known as ACHIEVE factors were selected as the base model. Hersey and Goldsmith (1980) designed the model to help managers determine the cause of performance problems and provide strategies for changing and solving the problems. In developing this model to analyze human performance, we had 
two main goals in mind: Determining the major factors that affect the performance of individual staff and offering these factors to the managers to keep them in mind and use them.

The first step in developing this model is the exclusion of factors that affect the performance management. Atkinson and Reitman (1956) confirmed that performance is influenced by incentive and ability. In simple terms, employees should have the desire and skills to complete the task. This idea was developed by adding the notion of knowledge or understanding jobs. However, even if the employee has a full desire or skills to do the job, that desire and skills will be useful only when they have a clear understanding of what they do and how they do it (Lawrence \& Loresch 1967).

Lawrence and Loresch (1967) dealt with this issue differently and concluded that performance is not solely related to the person's action features; it also relates to the organization and environment. Even with maximum incentive and skills people may not be effective, unless they receive the required organizational support and guidance and their job should be adapted to the needs of organizations and their environment.

This model uses two other factors of performance management. The first factor is evaluation and feedback that employees should be aware not only of what they should do, but also of how to act based on common issues. Feedback includes continuous training and formal evaluation of performance. Another factor is the management of validity. At current situation, managers should be able to make decisions that effectively influence people's jobs and provide necessary evidences and justification. In developed countries like America, staff's jobs need to be legally valid. Hersey and Goldsmith (1980) chose seven factors related to the effective performance management, namely incentive, ability, clarity of roles, organizational support, evaluation, validity, and environmental factors which are touched upon briefly below.

In this model, ability refers to the knowledge, experience, and skills to perform a particular task (Robbins, 2009). In fact, ability or willingness to work encompasses the knowledge and skills relevant to work (Hersey, Blancher, \& Johnson, 1996). The basic components of ability include working knowledge of the job (formal and informal apprenticeship facilitates the successful completion of the project) and the capability to do the job.

Clarity of the role (understanding the role) involves understanding and acceptance of work procedures; i.e., where and how it is done. The employees are required to have complete 
understanding of the organization's problems, main goals, and objectives. Besides, they should know how to achieve these goals and objectives and the organization's priorities must be quite explicit for employees (Rezaeeian, 1993).

Organizational support or help means supporting or assisting the employee to successfully perform the job. Some beneficial factors are sufficient funds, appropriate equipment and facilities, supports from other organizational units, the availability to qualified product, and adequate supply of human resources (Hersey, et al., 1996).

Incentive and willingness of staff refers to the employees' incentive to do their task or successfully complete the specific task of analysis (Hersey, et al., 1996). Many people are motivated to complete tasks when they get intrinsic or extrinsic rewards. If the employee has different types of incentive, the first step is to investigate the use of rewards and punishments.

Evaluation (feedback) applies to daily performance evaluation and to the occasional review. Continuous and proper feedback allows employee to be informed of the quality of his work (Haghighi, 2001). The purpose of this type of evaluation is daily informal presentation of performance to the employer as well as official periodic inspections (Rezaeeian, 1993).

The term staff validity introduces the appropriateness and legality of the manager's decision about human resources. The employees' decision must be accompanied by evidence and be based on the performance-oriented policy (Haghighi, 2001).

Appropriateness of environmental factors refers to the external factors accompanied with the ability, clarity, and support. Due to this, incentive affects job performance and environmental factors include competition, government regulations, and facilities (Haghighi, 2001).

\section{Research Question}

The following question guided this study:

Do the performance factors of the ACHIEVE model influence each other?

\section{Method}

This study was performed in a Web-based software manufacturing company in Iran where had about 60 employees. The population for the study consisted of 44 employees, 32 women (72.7\%) and 12 men (27.3\%) in four age groups, aged 20-25 (13 to 29.5\%), 26-30 (19 to 43.2\%), 31-35 (9 to 20.5\%) and 35 years old (3\% to 6.8\%). Among these, 4 people (9.1\%) had associate's degree, 31 people (70.5\%) had bachelor's degree, and 9 (20.5\%) possessed 
graduate degree. Thirty-seven people (84.1\%) had work experience of 5 years or less and 7 people (15.9\%) with the experience of 6 and 10 years were working in that company.

The research was an applied research and was conducted using survey method. Data was collected through ACHIEVE questionnaire related to ACHIEVE factors.

The questionnaire containing 27 questions was classified into seven factors which included ability, clarity, organizational support, incentive, evaluation and feedback, validity, and environmental factors. The questionnaire was arranged based on Likert scale. In this scale, the score one, two, three, four, and five were referred to totally disagree, disagree, I have no idea, agree, and totally agree, respectively. The questionnaires were distributed among 53 employees. A total of 45 returns were received. Of those returns, 44 were usable for further analysis. One questionnaire had to be discarded due to incompleteness.

To determine the reliability of measuring instruments, the Cronbach's alpha was used. Its value for the ability which included three items was 0.82 , the value for the clarity with 5 items was 0.90, and the value for the organizational support with 5 items was 0.72 . The values for the evaluation and feedback as well as for the factor validity, each with 4 items, were respectively 0.73 and 0.81 and for the environmental factors it was 0.72 . Cronbach's alpha calculated for all variables was greater than 0.7 which was indicative of the acceptable reliability for the collected data.

\section{Results}

To analyze the interactions between the performance factors, the correlation analysis was used. By multiplying the number of questions in the mean of Likert spectrum, the mean values were calculated. By comparing the median and the mean for the responses of each variable, it was observed that the average for the organizational support was lower than the average for other factors and the mean of other factors was more than average.

Comparing the mean and the median of the ability, it indicated that, on average, employees answered 'I agree' to the questions about the ability and according to their self-evaluation they had the ability to do their job. The clarity of the role clearly showed that the organizational goals were clear for the staff and they had clear understanding of their role within the organization. The mean of the organizational support was close to the average or it was even less than that. So, it demonstrated that, on average, employees did not have any idea about the organizational support or that they did not enjoy the organizational support. The difference between the mean and the median of incentive suggested that the employees were incentive 
to complete their work and work more efficiently. The results obtained for the factor of evaluation and feedback showed that according to the staff's idea, the managers were aware of their daily performance and offered the staff constructive suggestions to improve their performance. Investigating the factor of validity indicated that staff believed that they were allowed to make decisions and comment on the way they do their job. Minor differences between the mean and the median for environmental factors showed that, on average, staff had no opposite views about workplace and it was not boring and satisfactory for them. Table 1 shows the description statistics for variables.

Table 1

The Description Statistics for Variables

\begin{tabular}{lccccc}
\hline & Factors & The Number of Items & Median & Mean & Standard Deviation \\
\hline 1 & Ability & 3 & 9 & 12.4 & 1.9 \\
2 & Clarity of Role & 5 & 15 & 17.7 & 3.8 \\
3 & Organizational Support & 5 & 15 & 9.9 & 3.6 \\
4 & Incentive & 3 & 9 & 13.5 & 3.1 \\
5 & Evaluation and Feedback & 4 & 12 & 12.1 & 3.6 \\
6 & Validity & 4 & 9 & 9.1 & 2.7 \\
7 & Environmental Factors & 3 & & \\
\hline
\end{tabular}

To evaluate the relationship and the impact of factors on each other, the Pearson correlation test was used at 95\% level. The results of Pearson correlation test is shown in Table 2. The results showed a significant difference for the correlation coefficient of zero. The ability had no significant correlation with other factors and also had no multiplicative or reducing interaction. In general, the validity had high multiplicative interaction with other factors. Among the significant correlations, the correlation between clarity of the role and validity with the value of 0.52 was the highest value and the lowest correlation was between incentive and validity possessing the value of 0.27 .

Table 2

Results of Pearson Correlation Test

\begin{tabular}{cccccccc}
\hline & $\begin{array}{c}\text { Environmental } \\
\text { Factor }\end{array}$ & Validity & Evaluation & Incentive & $\begin{array}{c}\text { Organizational } \\
\text { Support }\end{array}$ & Clarity of Role & Ability \\
\hline Ability & 1 & & & & & & \\
Clarity of Role & 0.079 & 1 & & & & & \\
Organizational Support & -0.013 & 0.41 & 1 & & & & \\
Incentive & 0.217 & 0.19 & 0.43 & 1 & & \\
Evaluation & -0.048 & 0.42 & 0.47 & 0.24 & 1 & 1 \\
Validity & 0.160 & 0.52 & 0.42 & 0.27 & 0.42 & 0.437 & 1 \\
Environmental Factor & -0.019 & 0.12 & 0.48 & 0.40 & 0.46 & & \\
\hline
\end{tabular}

Table 3 shows the interaction between performance factors of ACHIEVE model. 
Table 3

Impacting and Being Impacted by Other Variables

\begin{tabular}{|c|c|c|c|}
\hline & Factors & Being affected & Affecting \\
\hline 1 & Ability & - & - \\
\hline 2 & Clarity of the Role & Evaluation and Feedback & $\begin{array}{c}\text { Validity } \\
\text { Organizational Support }\end{array}$ \\
\hline 3 & Organizational Support & $\begin{array}{l}\text { Evaluation and Feedback } \\
\text { Clarity of the Role }\end{array}$ & $\begin{array}{l}\text { Environmental Factor } \\
\text { Incentive } \\
\text { Validity }\end{array}$ \\
\hline 4 & Incentive & $\begin{array}{c}\text { Organizational Support } \\
\text { Environmental Factor } \\
\text { Validity }\end{array}$ & - \\
\hline 5 & Evaluation and Feedback & Environmental Factor & $\begin{array}{c}\text { Organizational Support } \\
\text { Validity } \\
\text { Clarity of the Role }\end{array}$ \\
\hline 6 & Validity & $\begin{array}{l}\text { Clarity of the Role } \\
\text { Organizational Support } \\
\text { Evaluation and Feedback }\end{array}$ & $\begin{array}{l}\text { Environmental Factor } \\
\text { Incentive }\end{array}$ \\
\hline 7 & Environmental Factor & $\begin{array}{c}\text { Organizational Support } \\
\text { Validity }\end{array}$ & $\begin{array}{l}\text { Evaluation and Feedback } \\
\text { Incentive }\end{array}$ \\
\hline
\end{tabular}

\section{Discussion}

According to the ACHIEVE model, ability, clarity of roles, organizational support and help, incentive or motivation, evaluation and feedback, validity, and environmental factors affect employee performance. The purpose of this study was to evaluate the interaction among these performance factors. The clarity of the role impacted organizational support. When an individual is aware of organization's objectives as well as his own role and responsibilities, he will have a more transparent relationship with the organization and will perceive more organizational support.

Evaluation and feedback affected the clarity of the role. Evaluating staff makes employees be more aware of their role and responsibilities within the organization. If an employee is not aware of his role and duties, by evaluating periodically and notifying him of his strengths and weaknesses will make employee more aware of his role and responsibilities in the organization.

Clarity of the role influenced validity. Considering the organization's objectives, if the staff is aware of his roles and responsibilities, he will feel more validity especially if agreement on performance objectives exists. The more the staff's validity, the more they make comment and determine how to do their tasks. Employees have the right to comment on how to perform their duties when get aware of their role and duties as well as organization's objectives. Organizational support had an influence on employee's incentive. The more employees receive the organizational support, the more increase is observed in employees' incentive and thereby it makes employees work more efficiently and complete the job. 
Evaluation and feedback affected the organizational support. Periodic performance appraisal, notifying employees of their strengths and weaknesses as well as offering constructive suggestions improve their performances and subsequently, employees receive more organizational support. Besides, organizational support influenced validity. Employees who receive more organizational support are allowed to take risks. Therefore, they are entitled to make comment on determining new job duties.

Organizational support had a direct effect on the environment. Workplace conditions are appropriate for staff that receive more organizational support and are allowed to take risks and get required equipment; therefore, employees do not get tired of working in such an environment. In addition, validity had a low impact on employees' incentive. Whenever employees have the right to have a say in determining their responsibilities, to develop a job description, and decide collectively, they create incentive to complete the work and do the more optimal work. Following this, environmental factors directly affected the employees' incentive. When workplace conditions are appropriate for staff and they get the required equipment, employees do not get tired of working in such environment and do their work with strong sense. Also, they show themselves more incentive to complete the work and do the optimal work.

Evaluation and feedback had a direct effect on validity. This highlights that when the manager is aware of the employees' daily performance, he can give constructive suggestions to improve staff's performance and also notify the employee of his strengths and weaknesses. Whatever the periodic performance appraisal be high, they can comment more on the way of doing their job and developing a job description.

Environmental factors, also, had a direct influence on the evaluation of the staff. When the desirable conditions of work exist in a workplace for doing the determined tasks where the staff is provided with the required equipment, employees enjoy working in such environment, and this will affect performance as well as performance evaluation. In addition, validity had a direct effect on the environment. This means that when the employees have the right to have a say in determining job responsibilities and to decide collectively on the way they work, they feel better in that workplace, thereby they do not get tired of working in that place.

\section{Conclusion}

The results indicated that the ability had no impact on other factors and was not influenced by any other factors. The clarity of the role influenced organizational support and validity. The 
impact of the validity factor was more than the impact of the clarity of the role on organizational support. Incentive influenced other factors and it was influenced by organizational support, validity, and environmental factors. This consideration implies that incentive was influenced more by organizational support, environmental factors, and validity, respectively. Evaluation and feedback had the greatest impact first on organizational support, then on the clarity of the role, and finally on validity. Also, environmental factors were influenced by the evaluation and feedback.

Moreover, validity had the greatest impact on the environment and then affected incentive. Factors affecting validity include clarity of role, evaluation and feedback, and organizational support, respectively. Environmental factors affected evaluation and feedback, incentive, organizational support, and validity.

The results suggested that in order to improve employees' performance, managers should give priority to validity and organizational support. Additionally, the ability of employees as an independent factor should be improved especially by training and development. Environmental factors and feedback are in the third priority. Incentive and clarity of roles may be provided when we deal with other factors and can be placed in the last priority.

The findings of this study showed that performance factors of ACHIEVE were not completely independent of each other and in some cases they had multiplicative interactions. The results proved that the factor of ability had no multiplicative or reducing interaction with other factors. In the same line of the argument, no reducing interaction was detected between the factors. In the current study, significant attention was paid to knowing how the interaction between performance factors can be interpreted. However, future research should qualitatively examine how these factors can affect each other. The recognition of the effects helps managers improve their performances. The sample size used in the study contained small number of individuals, so further studies should use larger samples and the findings need to be interpreted carefully with regard to generalizability.

\section{References}

Ammons, D. N., Liston, E. G., \& Jones, J. A. (2013). Performance management purpose, executive engagement, and reported benefits among leading local governments. State \& Local Government Review, 45(3), 172-179.

Armstrong, M. (2000). Performance management: Key strategies and practical guidelines (2 ${ }^{\text {nd }}$ ed.). London, UK: Kogan Page.

Atikson, J. W., \& Reitman, W. R. (1956). Performance as a function of motive strength and expectancy of soal-attainment. Journal of Abnormal \& Social Psychology, 53, 361-366.

Bititci, U., Coccab, P., \& Ates A. (2015). Impact of visual performance management systems on the performance management practice of organizations. International Journal of Production Research, 1, 1-23.

Cardy, R. L. (2004). Performance management: Concepts, skills, and exercises. Armonk, NY: M. E. Sharpe. 
Cho, Y. J., \& Lee, J. W. (2012). Performance Management and Trust in Supervisors. Review of Public Personnel Administration, 32(3), 236-259.

De Waal, A., Hafizi, R., Rahbar, A. H., \& Rowshan, S. (2010). Studying performance management in Iran using an adapted performance management analysis. Journal of Transnational Management, 15, 246-264.

Delery, J. E., \& Doty, D. H. (1996). Modes of theorizing in strategic human resources management: Test of universalistic, contingency, and configurational performance predictions. Academy of Management Journal, 39(4), 802-835.

Haghighi, M. A. (2001). Organizational behavioral management. Tehran: Termeh.

Haines III, V. Y., \& St-Onge, S. (2012). Performance management effectiveness: Practices or context? International Journal of Human Resource Management, 23(6), 1158-1175.

Helden, G. J., Johnsen, A. \& Vakkuri, Å. (2012). The life-cycle approach to performance management: Implications for public management and evaluation. Evaluation, 18(2), 159-175.

Hersey, P., \& Goldsmith, M. (1980). A situational approach to performance planning. Training \& Development Journal, 34(11), 38-44.

Hersey, P., \& Blanchard, K. H., Johnson, D.E. (1996). Management of organizational behavior: Utilizing human resource. Upper Saddle River, NJ: Prentice Hall.

Jacobsen, Ch. B., \& Andersen, L. B. (2014). Performance management in the public sector: Does it decrease or increase innovation and performance? International Journal of Public Administration, 37(14), 1011-1023.

Lawrence, P., \& Lorsch, J. (1967). Differentiation and integration in complex organizations. Administrative Science Quarterly, 12(1), 1-30.

Moynihan, D. P., \& Pandey, S. K. (2005). Testing how management matters in an era of government by performance management. Journal of Public Administration Research \& Theory, 15(3), 421-439.

Moynihan, D. P., \& Pandey, S. K. (2010). The big question for performance management: Why do managers use performance information? Journal of Public Administration Research \& Theory, 20(4), 849-866.

O’Boyle, I, \& Hassan, D. (2014). Performance management and measurement in national-level non-sport organizations. European Sport Management Quarterly, 14(3), 229-314.

Pulakos, E. D. (2009). Performance management: A new approach for driving business results. Malden, MA: WileyBlackwell.

Rezaeeian, A. (1993). Organizational behavioral management: Concepts, skills, and exercise. Tehran: Tehran University Press.

Robbins, S. P. (2009). Organizational behavior. San Diego: San Diego State University.

Sun, R., \& Van Ryzin, G. G. (2014). Are performance management practices associated with better outcomes? Empirical evidence from New York Public Schools. American Review of Public Administration, 44(3), 324-338.

Wholey, J. S. (2001). Managing for results: Roles for evaluators in a new management era. American Journal of Evaluation, 22(3), 343-347. 